OPEN ACCESS

Edited by:

Michael Sweet,

University of Derby, United Kingdom

Reviewed by:

Simon K. Davy,

Victoria University of Wellington, New

Zealand

Melissa Susan Roth,

University of California, Berkeley,

United States

${ }^{*}$ Correspondence:

Caroline V. Palmer

carolinepalmer28@gmail.com

Specialty section:

This article was submitted to

Coral Reef Research,

a section of the journal

Frontiers in Marine Science

Received: 29 April 2018

Accepted: 29 June 2018

Published: 18 July 2018

Citation:

Palmer CV (2018) Warmer Water Affects Immunity of a Tolerant Reef

Coral. Front. Mar. Sci. 5:253.

doi: 10.3389/fmars.2018.00253

\section{Warmer Water Affects Immunity of a Tolerant Reef Coral}

\author{
Caroline V. Palmer* \\ School of Biological and Marine Sciences, University of Plymouth, Drake Circus, Plymouth, Devon, United Kingdom
}

Corals are multipartite sedentary organisms, which have evolved complex, physiological networks in order to survive perturbations and environmental fluctuations. However, climate change is warming tropical waters, pushing the limits of coral tolerance and driving global declines. Coral susceptibility to thermal anomalies is variable among species and through time, and directly relates to constituent immunity. Constituent immunity refers to immune activities required to ensure homeostasis, whereas an immune response is acutely heightened immune activity to a perturbation. Understanding the mechanisms behind coral health, and sustained health through adverse conditions, is increasingly important for establishing effective reef conservation and restoration projects. However, most experimental studies of coral health use species that are highly susceptible to thermal events, potentially skewing our understanding. To determine the influence of warmer water on immunity, activities of key coral immune pathways and an antioxidant were compared under ambient $\left(27^{\circ} \mathrm{C}\right)$ and warmer water $\left(32^{\circ} \mathrm{C}\right)$, and between injured and uninjured (control) branches of the tolerant reef coral Porites cylindrica. Three types of phenoloxidase, mono-phenoloxidase, ortho-diphenoloxidase and para-diphenloxidase, indicative of two melanin synthesis pathways (the tyrosinase and laccase-type), and peroxidase were measured at 0 (control), 1, 6, 24, 48, and 168 h post-injury. All four enzymes demonstrated consistent levels of activity under ambient conditions $\left(27^{\circ} \mathrm{C}\right)$, indicating constituent immunity. Upon injury at ambient temperature, all enzyme activities were significantly higher $1 \mathrm{~h}$ post-injury as compared to uninjured controls, demonstrating a comprehensive immune response to tissue disruption. Under warmer water, constituent immunity increased through time indicative of immune modulation to maintain homeostasis. However, warmer water, within the non-bleaching summer range, suppressed the immune response to injury, delaying it by $24 \mathrm{~h}$. Therefore, upon the environmental cue of warmer water, the tolerant coral $P$. cylindrica may divert resources away from immune responses (immunosuppression) while enhancing constituent immunity (immune modulation) so as to maintain health through sub-optimal conditions. These changes in immunity with warmer water demonstrate that temperature affects coral immunity and, for this tolerant coral, triggers immune-modulation that may provide cross-tolerance to perturbations more frequent in summer months, such as bleaching and disease.

Keywords: coral, immunity, tolerance, immunosuppression, climate change, bleaching, immune modulation 


\section{INTRODUCTION}

Immunity underpins organism health and survival and determines tolerance (Sheldon and Verhulst, 1996; Palmer et al., 2010; Palmer, 2018). Accelerating climate change, due to global carbon emissions, is challenging the survival of reef corals, and therefore the persistence of functional coral reefs (Hughes et al., 2018a). Tropical waters are warming to temperatures beyond the range of normal diurnal and seasonal fluctuations historically experienced by reef corals. This shift is more frequently inducing breakdowns in the mutualism between the coral and microscopic algae, Symbiodinium spp., known as coral bleaching (Hughes et al., 2018b). Corals have differing tolerances to shifts in thermal regimes, as evidenced by the variable extent of bleaching among corals during extreme thermal events (Marshall and Baird, 2000; van Woesik et al., 2011; Hughes et al., 2018a). This variation suggests that coral holobiont immune systems, as proponents of survival and determinants of tolerance, are variably effective and are being increasingly pushed to and beyond their limits (Palmer et al., 2010, 2012).

Immunity is costly with energetic investment consequently being diverted away from other life history traits such as reproduction and growth (Sheldon and Verhulst, 1996). Immune system activity is therefore dynamic in the pursuit of optimal health, operating with finite resources under fluctuating biotic and abiotic conditions. Immunity also incurs the cost of selfharm, known as autoimmunity, and the additional resource costs required to mitigate or recover from it (Sadd and SchmidHempel, 2009). Therefore, at any given time, the manifestation of organism immunity, such as that of the coral holobiont, represents current physiological trade-offs operating under evolutionary constraints i.e., Life history trade-offs (Sadd and Schmid-Hempel, 2009; see Palmer, 2018).

There are two aspects of organism immunity. One is constituent immunity that maintains holobiont homeostasis under normal, fluctuating conditions. Constituent immunity provides surveillance and maintenance in the absence of an infection or acute perturbation-similar to our circulating white blood cells (Tauber, 2015). Levels of coral constituent immunity relates directly to both bleaching and disease susceptibility (Palmer et al., 2010). The second aspect of immunity is the immune response. This is acute, localized heightened immune activity in the presence of a threat so as to reestablish homeostasis (Pastori and Foyer, 2002; Tauber, 2015; Foyer et al., 2016). Of these, constituent immunity provides continual health maintenance at low cost, whereas an immune response provides acute protection incurring comparatively high cost (Sheldon and Verhulst, 1996; Sadd and Schmid-Hempel, 2009). Therefore, immune responses are used sparingly, are tightly controlled (Sheldon and Verhulst, 1996) and are a balanced consequence of signaling, organism condition and overall immune strategy (Lazzaro and Rolff, 2011; Palmer, 2018).

Corals are sedentary, multipartite organisms that have evolved complex, integrated physiological systems to survive fluctuations in local environmental conditions, predation and disease (e.g., Miller et al., 2007; Palmer and Traylor-Knowles, 2012; Mydlarz et al., 2016). As such, differing immune strategies have likely evolved among corals to maintain optimal fitness while mitigating the energetic and autoimmune costs in upregulating an immune response (Palmer et al., 2010, 2011c). Various coral immune strategies, and their efficacies, are therefore evident in comparative tolerances to perturbations (Palmer, 2018), such as thermal events (e.g., Hawkins et al., 2014, 2015; Hughes et al., 2018a). However, coral stress and health studies are predominantly conducted on fast growing, branching coral species e.g., Acropora spp. (Moya et al., 2012; van de Water et al., 2015a; Traylor-Knowles et al., 2017) and Pocillopora spp. (Sogin et al., 2016), with few exceptions (e.g., Fuess et al., 2017). The well-studied fast-growing coral genera have amongst the lowest levels of constituent immunity and are the most susceptible to disease and bleaching (Palmer et al., 2010, 2012). It is likely, therefore, that the immune strategy of these susceptible corals to perturbations differs from that of coral species with higher constituent immunity that are more tolerant of them (Palmer, 2018). By focusing research efforts on the immune responses of these susceptible corals, our information on coral tolerance, resistance and, ultimately, reef resilience as a whole may be both skewed and underestimated (Palmer, 2018).

Corals, as other invertebrates, use phenoloxidase cascades, also known as melanin synthesis pathways, as mainstays of immunity (Cerenius et al., 2010; Palmer and Traylor-Knowles, 2012). Several types of phenoloxidase cascades have been identified in multiple corals, as determined by enzymatic activity using different substrates (Palmer et al., 2012) and corroborated by gene searches within available coral genomes (Palmer, unpublished). Of the phenoloxidase pathways, the more cytotoxic tyrosinase type is the better understood within invertebrates in general, and involves both mono-phenoloxidase and $o$-diphenoloxidases to resist infection (Cerenius et al., 2010; Mydlarz and Palmer, 2011; Palmer et al., 2012). The laccasetype phenoloxidase pathway, indicated by $p$-diphenoloxidase activity, is likely involved in reinforcing damaged tissue and may have a sensory function (Mydlarz and Palmer, 2011; Palmer et al., 2012). Both pathways have the potential to deposit melanin-a redox-active brown/black pigment that absorbs light. Found within mobile coral cells, melanin may offer photoprotection of algal endosymbionts and mitigate bleaching (Palmer et al., 2010). The phenoloxidase pathways produce cytotoxic radicals, particularly the tyrosinase type, which must be tightly controlled to avoid autoimmunity (Cerenius et al., 2010). Immunity-induced oxidative stress and that experienced during warmer water and high light conditions, can be mitigated with increased antioxidant activity (Hawkins et al., 2015). Coral antioxidants include catalase, superoxide dismutase, peroxidase and fluorescent proteins, and may be used to maintain health by reducing autoimmunity and limiting self-harm (Palmer et al., 2009b; Mydlarz and Palmer, 2011; Hawkins et al., 2015).

With the intention to better elucidate how warmer water may affect coral immunity, constituent immunity and the immune responses of a tolerant Indo-Pacific reef-building coral species, Porites cylindrica, were investigated. The activities of three phenoloxidases (PO) as well as the antioxidant peroxidase were measured in response to injury at both ambient and elevated temperature. 


\section{METHODS}

\section{Sample Collection}

Large, $>50 \mathrm{~cm}$ diameter, and visibly healthy colonies of brown Porites cylindrica were located on the upper reef slope $(\sim 1-2 \mathrm{~m}$ depth) in Pioneer Bay at Orpheus Island, Great Barrier Reef (GBR), Australia, and sampled in May 2008. From each of three colonies of $P$. cylindrica, 60 branches were removed $(\operatorname{Tn}=180)$ and transported in $1 \mu \mathrm{m}$ filtered seawater to the laboratory.

\section{Experimental Set-Up}

Six aquaria within temperature-controlled rooms at Orpheus Island Research Station were supplied with flow-through filtered seawater $(1 \mu \mathrm{m})$ at ambient temperature $\left(27^{\circ} \mathrm{C}\right)$, and with $12 \mathrm{~h}$ light/12 h dark light regimes using metal halide lights, with light levels maintained at $150-250 \mu \mathrm{mol}$ quanta $\mathrm{m}^{-2} \mathrm{~s}^{-1}$. Three aquaria were each designated to ambient or elevated temperature treatments, and the 180 coral branches were randomly allocated among them. Coral branches were held upright using labeled plastic clothes pegs. All six aquaria were maintained at ambient conditions for 3 days to allow branches to recover from samplingwounds seal in this species in $48 \mathrm{~h}$ (Palmer et al., 2011b)and to acclimate to aquaria conditions. On day four, three branches from each colony were randomly selected and placed into liquid nitrogen as pre-treatment controls $(0 \mathrm{~h})$, and stored at $-30^{\circ} \mathrm{C}$. Water temperatures in three of the aquaria were then increased by 1 to $1.5^{\circ} \mathrm{C}$ per day, for 3 days and stabilized at $32^{\circ} \mathrm{C}$. After 2 days at $32^{\circ} \mathrm{C}$, three branches from each colony were sampled randomly from both elevated and control temperature treatments. A wound was then created on half of the remaining branches using bone-cutters to score a ring of damage approximately $2.5 \mathrm{~mm}$ deep, $1 \mathrm{~cm}$ below the branch tip. Three injured branches and three non-injured (control) branches were sampled from each colony per temperature treatment at $1,6,24,48$, and $168 \mathrm{~h}$ (7 d) post-injury. All samples were immediately snap-frozen in liquid nitrogen and stored at $-30^{\circ} \mathrm{C}$. For the duration of the experiment no mortality occurred and all coral branches appeared healthy with no visible paling (loss of zooxanthellae) or infection.

\section{Biochemical Analyses}

A $\sim 6$ polyp-wide band of tissue surrounding the lesion was removed, and from equivalent areas on control branches, using an airgun with $100 \mathrm{mmol}^{-1}$ phosphate buffer with 5 mmol.1 ${ }^{-1}$ 2-mercaptoethanol (Sigma-Aldrich M7522; Palmer et al., 2008). While 2-mercaptoethanol has some inhibitory effect on phenoloxidase activity, the low concentration and methods ensured this was minimal and consistent among samples, making them directly comparable. Tissue from branch tips and bases were avoided. Resulting tissue slurries were frozen in liquid nitrogen and stored at $-30^{\circ} \mathrm{C}$. Thawed samples were homogenized using a vortex with glass beads for $1 \mathrm{~min}$ and centrifuged for $5 \mathrm{~min}$ to remove tissue debris, glass beads and the zooxanthellae. Supernatants were carefully removed and aliquots stored at $-30^{\circ} \mathrm{C}$. All samples were treated the same, ensuring direct comparability among samples despite any inadvertent PO degradation during processing.
Phenoloxidase (PO) activities were quantified as change in absorbance (at $410 \mathrm{~nm}$ ) over time using the substrates: tyramine (Fluka 93810) for mono-phenoloxidase activity, dopamine hydrochloride (Sigma-Aldrich H8502) for o-diphenoloxidase activity and hydroquinone (Sigma H9003) for $p$-diphenoloxidase activity (as per Palmer et al., 2012). For each of the PO assays, three $10 \mu \mathrm{l}$ aliquots of each sample extract were placed in wells of a clear 96-well microtiter plate. To each well, $50 \mu \mathrm{l}$ of $50 \mathrm{mmol}^{-1}$ phosphate buffer ( $\mathrm{pH}$ 7.5) and $25 \mu \mathrm{l}$ of deionized water (DI) were added. Plates were then covered and incubated at either $27^{\circ} \mathrm{C}$ or $32^{\circ} \mathrm{C}$, depending on the experimental treatment regime of each sample, for $15 \mathrm{~min}$ in order to record the activity of enzymes under experimental treatment conditions. The appropriate substrate (30 $\mathrm{ul}$ of $50 \mathrm{mmol}^{-}$) was then added and the change in absorbance for each well, including blank controls, was measured at $410 \mathrm{~nm}$ for $45 \mathrm{~min}$. Peroxidase activity was measured by adding $40 \mu \mathrm{l}$ of guaiacol $\left(25 \mathrm{mmol} . \mathrm{l}^{-1}\right)$ to $10 \mu \mathrm{l}$ of sample and $35 \mu \mathrm{l}$ of $50 \mathrm{mmol}^{-1}$ phosphate buffer $(\mathrm{pH}$ 6.0). The reaction was activated by the addition of $25 \mu \mathrm{l}$ of $\mathrm{H}_{2} \mathrm{O}_{2}$ $\left(20 \mathrm{mmol} \cdot \mathrm{l}^{-1}\right)$ and measured at $470 \mathrm{~nm}$ for $45 \mathrm{~min}$. For each sample, the change in absorbance was calculated for the linear portion of the reaction curve and standardized to total protein concentration, as determined by the Quick Start Bradford assay (Bio-Rad).

Protein activities were compared between injury treatments (uninjured or injured) and temperature treatments $\left(27^{\circ} \mathrm{C}\right.$ or $32^{\circ} \mathrm{C}$ ) using two-way repeated measures ANOVAs, executed using log-transformed data in SPSS. Data satisfied assumptions of sphericity, as determined with Mauchley's test, and homogeneity of covariance as determined by Box's test.

\section{RESULTS}

Porites cylindrica demonstrated significantly higher monophenoloxidase activity in injured than uninjured samples at ambient seawater temperatures $\left(27^{\circ} \mathrm{C}\right)$ (Table 1 and Figure 1A). Heightened mono-phenoloxidase activity was particularly noticeable $1 \mathrm{~h}$ post-injury, when it was 4.5 -fold greater than for uninjured branches, indicating the rapid activation of an immune response. Levels of mono-phenoloxidase activity were similar between injured and uninjured branches between 6 and $168 \mathrm{~h}$, (Table 1). At elevated water temperature (Figure 1B), there was no difference in mono-phenoloxidase activity between injured and uninjured branches, at any time point (Table 1), indicating a lack of response of this enzyme to injury in warm waters. However, mean mono-phenoloxidase activity of uninjured branches increased by approximately 3 -fold over time in the elevated temperature treatment (Table 1), which was absent in the ambient water temperature treatment (Figure 1). Injured branches demonstrated a peak of activity at $24 \mathrm{~h}$ post-injury with elevated water temperature (Figure 1B), which was similar in magnitude to the peak of activity at $24 \mathrm{~h}$ post-injury in the injured treatment at ambient water temperature. Consistently, mono-phenoloxidase activity of injured branches over time was dependent on temperature (temperature x time, Table 2). 
TABLE 1 | A summary of the $F$ - and $P$-values results of the two-way repeated measures ANOVAs examining the effects of injury (uninjured controls vs. injured samples) and time post-injury $(1,6,24,48$, and $168 \mathrm{~h})$, and their interaction on immunity protein activity for both ambient $\left(27^{\circ} \mathrm{C}\right)$ and elevated $\left(32^{\circ} \mathrm{C}\right)$ temperatures.

\begin{tabular}{|c|c|c|c|c|c|c|c|c|c|c|c|c|}
\hline \multirow[t]{3}{*}{ Immunity enzyme } & \multicolumn{4}{|c|}{ Injury $(d f=1,10)$} & \multicolumn{4}{|c|}{ Time $(d f=4,10)$} & \multicolumn{4}{|c|}{ Injury $\times$ time $(d f=4,10)$} \\
\hline & \multicolumn{2}{|c|}{ Ambient } & \multicolumn{2}{|c|}{ Elevated } & \multicolumn{2}{|c|}{ Ambient } & \multicolumn{2}{|c|}{ Elevated } & \multicolumn{2}{|c|}{ Ambient } & \multicolumn{2}{|c|}{ Elevated } \\
\hline & $\boldsymbol{F}$ & $P$ & $\boldsymbol{F}$ & $P$ & $\boldsymbol{F}$ & $P$ & $\boldsymbol{F}$ & $P$ & $\boldsymbol{F}$ & $P$ & $\boldsymbol{F}$ & $P$ \\
\hline Mono-PO & 5.4 & 0.04 & 0.01 & 0.93 & 3.1 & 0.69 & 6.8 & $<0.01$ & 3.0 & 0.07 & 0.5 & 0.84 \\
\hline o-diPO & 4.7 & 0.06 & 0.6 & 0.48 & 0.5 & 0.71 & 8.3 & 0.03 & 1.1 & 0.40 & 1.7 & 0.23 \\
\hline$p$-diPO & 3.5 & 0.09 & 0.1 & 0.78 & 2.7 & 0.09 & 0.9 & 0.49 & 2.3 & $<0.01$ & 4.5 & 0.03 \\
\hline Peroxidase & 13.8 & 0.04 & 0.01 & 0.92 & 2.8 & 0.09 & 8.0 & $<0.01$ & 1.6 & 0.25 & 2.0 & 0.18 \\
\hline
\end{tabular}

$P$ values $<0.05$ are in bold.
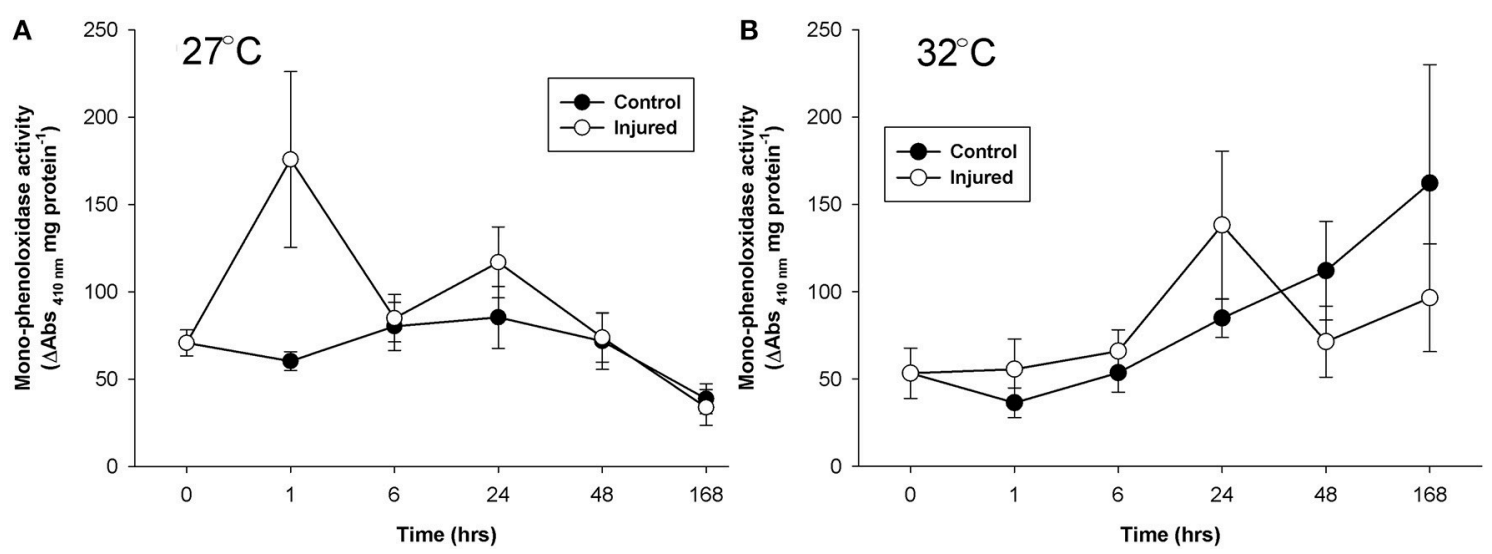

FIGURE 1 | Mean mono-phenoloxidase activity ( \pm SE) for uninjured (control) and injured branches of $P$. cylindrica at: (A) ambient $\left(27^{\circ} \mathrm{C}\right)$, and $(\mathbf{B})$ elevated $\left(32^{\circ} \mathrm{C}\right)$ water temperature over time post-injury.

Mean o-diphenoloxidase activity at ambient water temperature did not differ significantly between injury treatments, or over time (Figure 2A, Table 1). However, at both 1 and 24 h post-injury, $o$-diphenoloxidase activity was more than 2-fold higher in the injured treatment than the control treatment. This indicates a rapid response of $o$-diphenoloxidase activity to injury, which was sustained for $24 \mathrm{~h}$. At elevated water temperature (Figure 2B), there was no difference in $o$-diphenoloxidase activity between injured and uninjured branches (Table 1), indicating no immediate response to injury. However, at elevated water temperature o-diphenoloxidase activity in uninjured samples at $24 \mathrm{~h}$ was equivalent to that of the injured ambient samples (Figure 2B), suggesting that the response of $o$-diphenoloxidase activity is delayed at higher temperatures. Additionally, and similar to the monophenoloxidase activity, control levels of $o$-diphenoloxidase activity significantly increased over time by approximately 4 -fold at elevated water temperature (Table 1) and overall were higher than control levels at ambient water temperature (Table 2). This indicates a response of $o$-diphenoloxidase activity to warmer water.

Mean $p$-diphenoloxidase activity with injury depended upon the time post-injury at both ambient and elevated water temperature (injury $\times$ time, Table 1 ) and the timing of activity in response to injury significantly varied between the water temperature treatments (Time, Table 2). At ambient water temperature $p$-diphenoloxidase activity of injured samples at 1 and $24 \mathrm{~h}$ post-injury was approximately 3-fold and 2.5fold higher than controls, respectively (Figure 3A). This upregulation in activity indicates a direct response of laccase-type PO activity to injury. At elevated water temperature (Figure 3B), there was a trend of increasing $p$-diphenoloxidase activity over time in the control treatment, although this was not significant (Time, Table 1).

At ambient water temperature, mean peroxidase activity (Figure 4A) was significantly higher in the injured treatment as compared to the control treatment (Injury, Table 1). There was a 25 -fold increase in peroxidase activity with injury at $1 \mathrm{~h}$ at ambient water temperature, which remained up-regulated, compared to controls, for $48 \mathrm{~h}$, demonstrating a direct and sustained response of this antioxidant to injury. At elevated water temperature (Figure 4B), there was no significant difference in peroxidase activity between controls and injured samples (Injury, Table 1), although activity varied over time post-injury (Time, Table 1). Overall, peroxidase activity differed significantly with the temperature treatments over time (Temperature $\mathrm{x}$ time, Table 2), and control levels of activity were significantly higher at elevated water temperature as compared to ambient, likely driven 
TABLE 2 | A summary of the $P$-values results of the two-way repeated measures ANOVAs examining the effects of temperature (ambient $27^{\circ} \mathrm{C}$ vs. elevated $32^{\circ} \mathrm{C}$ ) and time post-injury $(1,6,24,48$, and $168 \mathrm{~h})$, and their interaction on immunity protein activity for both uninjured controls and injured samples.

\begin{tabular}{|c|c|c|c|c|c|c|c|c|c|c|c|c|}
\hline \multirow[t]{3}{*}{ Immunity enzyme } & \multicolumn{4}{|c|}{ Temperature $(\mathrm{df}=1,10)$} & \multicolumn{4}{|c|}{ Time $(\mathrm{df}=4,10)$} & \multicolumn{4}{|c|}{ Temperature $\times$ time $(\mathrm{df}=4,10)$} \\
\hline & \multicolumn{2}{|c|}{ Control } & \multicolumn{2}{|c|}{ Injured } & \multicolumn{2}{|c|}{ Control } & \multicolumn{2}{|c|}{ Injured } & \multicolumn{2}{|c|}{ Control } & \multicolumn{2}{|c|}{ Injured } \\
\hline & $\boldsymbol{F}$ & $P$ & $F$ & $P$ & $\boldsymbol{F}$ & $P$ & $\boldsymbol{F}$ & $P$ & $\boldsymbol{F}$ & $P$ & $F$ & $P$ \\
\hline Mono-PO & 0.1 & 0.73 & 1.5 & 0.25 & 2.1 & 0.15 & 0.6 & 0.70 & 2.8 & 0.08 & 5.5 & 0.01 \\
\hline o-diPO & 5.5 & 0.04 & 0.01 & 0.83 & 1.0 & 0.45 & 2.4 & 0.12 & 1.4 & 0.31 & 5.5 & 0.01 \\
\hline$p$-diPO & 4.7 & 0.06 & 0.05 & 0.83 & 1.4 & 0.30 & 3.8 & 0.04 & 1.6 & 0.26 & 1.1 & 0.41 \\
\hline Peroxidase & 11.0 & $<0.01$ & 7.5 & 0.02 & 1.0 & 0.44 & 4.5 & 0.02 & 0.8 & 0.53 & 6.0 & $<0.01$ \\
\hline
\end{tabular}

$P$ values $<0.05$ are in bold.
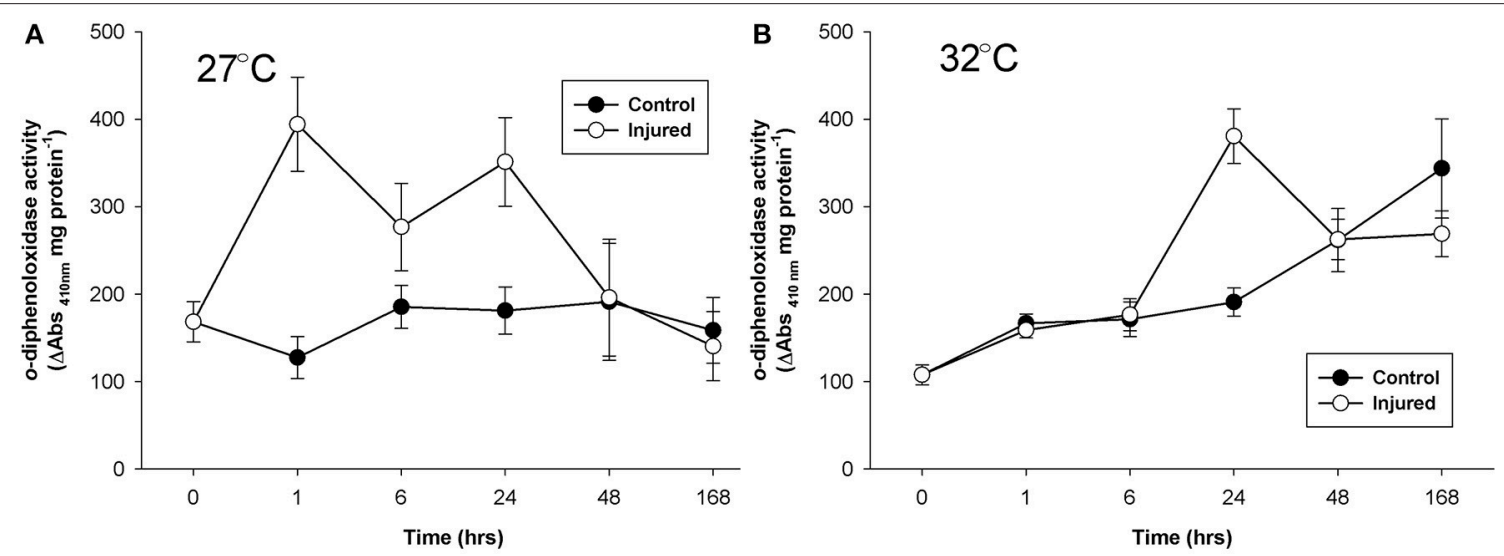

FIGURE 2 | Mean o-diphenoloxidase activity ( \pm SE) for uninjured (control) and injured $P$. cylindrica at: (A) ambient $\left(27^{\circ} \mathrm{C}\right)$ and, (B) elevated $\left(32^{\circ} \mathrm{C}\right)$ water temperature over time post-injury.

by the $6 \mathrm{~h}$ time point, whereas the reverse was true for the injured samples (Temperature, Table 2). These results demonstrate that peroxidase activity increases in response to both elevated water temperature and injury, but is suppressed when these treatments are combined.

\section{DISCUSSION}

Porites cylindrica demonstrated consistent activity of all investigated enzymes in the absence of injury at $27^{\circ} \mathrm{C}$, confirming the presence of constituent immunity and its stability under constant ambient conditions (Palmer et al., 2010; van de Water et al., 2016). An immune response occurred within $1 \mathrm{~h}$ of injury under ambient water temperature. Warmer water induced a gradual ramping of constituent immunity in control samples and the immune response to injury was altered as compared to ambient conditions. Elevated water temperature, within non-bleaching summer range, had an immuno-enhancing effect on constituent immunity but an immunosuppressive impact on the P. cylindrica immune response.

\section{Immune Response Under Ambient Conditions}

The constituent immunity levels of $P$. cylindrica, under ambient control conditions, remained approximately constant for the duration of the experiment, representing activities used to maintain homeostasis in the absence of a perturbation (Palmer et al., 2010; Tauber, 2015; Palmer, 2018). Of 18 Indo-Pacific hard coral species $P$. cylindrica has amongst the highest levels of constituent immunity (Palmer et al., 2012). Such investment into maintaining homeostasis fosters tolerance and promotes survival through both biotic and abiotic fluctuations and perturbations (Palmer, 2018).

The immune response of $P$. cylindrica to injury occurred within $1 \mathrm{~h}$ and was demonstrated by heightened activity of all four enzymes as compared to their constituent levels (Tauber, 2015). These results reconfirm the involvement of phenoloxidases and peroxidase in a $P$. cylindrica immune response (Palmer et al., 2008, 2011a) and are consistent with the timings of de-granulation of melanin-containing granular cells observed in P. cylindrica with injury (Palmer et al., 2011b). The tyrosinase-type phenoloxidase pathway (monophenoloxidase and $o$-diphenoloxidase) is highly cytotoxic, and therefore potentially plays a pathogen-killing or sterilization role at the wound site (van de Water et al., 2015b). The laccase-type pathway, indicated by $p$-diphenoloxidase activity, is less cytotoxic and likely used for structural reinforcement of injured coral tissue (Palmer et al., 2011b). Coincident with the increase in cytotoxic immune pathway activity was the corresponding heightened activity of the antioxidant peroxidase, a hydrogen peroxidescavenging enzyme. Peroxidase activity, serving a protective 

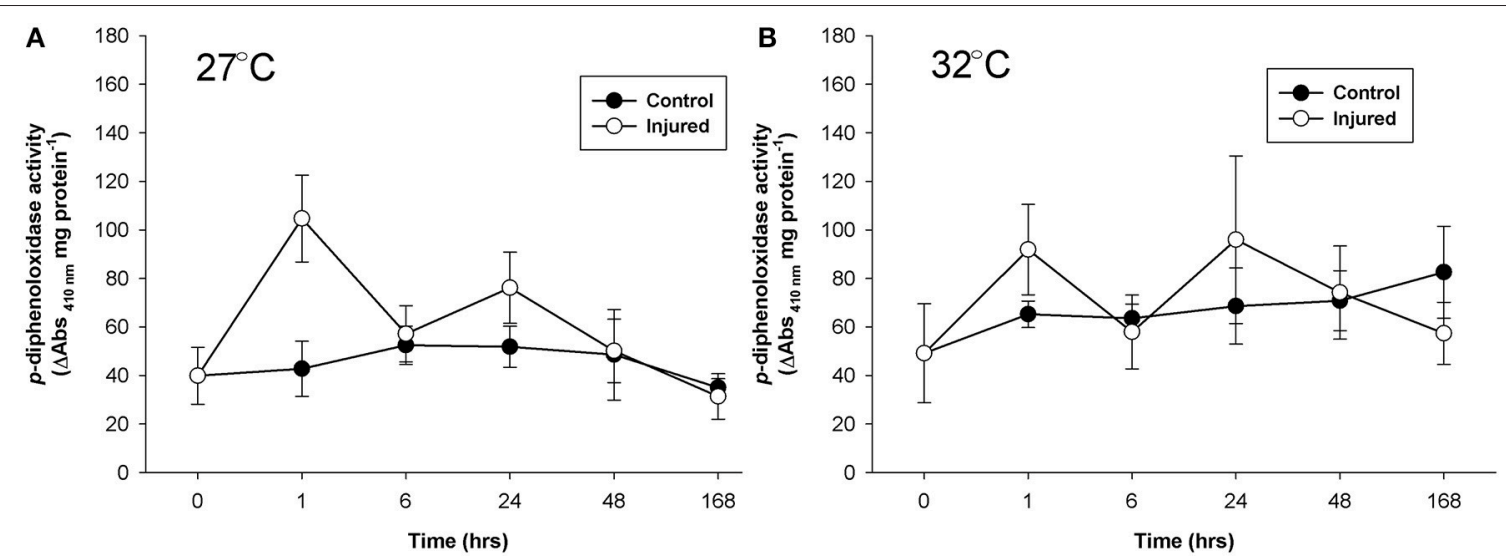

FIGURE 3 | Mean p-diphenoloxidase activity ( $(\mathrm{SE})$ for uninjured (control) and injured $P$. cylindrica at: $(\mathbf{A})$ ambient $\left(27^{\circ} \mathrm{C}\right)$ and $(\mathbf{B})$ elevated $\left(32^{\circ} \mathrm{C}\right)$ water temperature over time post-injury.
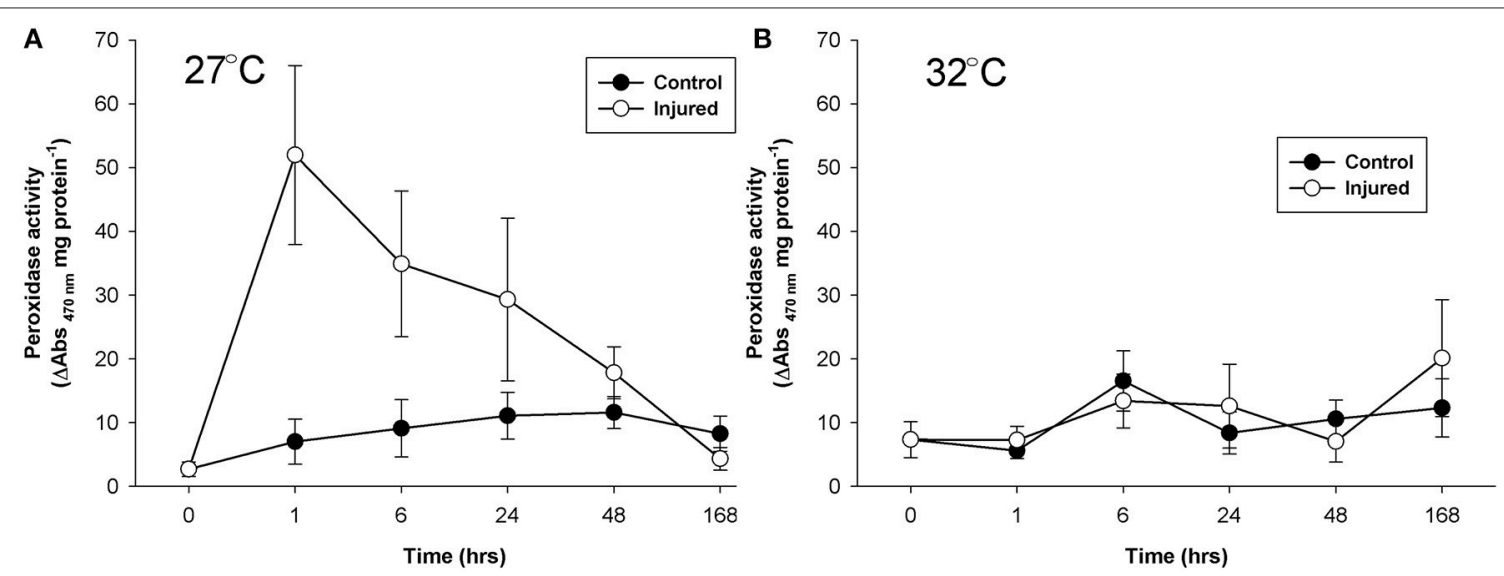

FIGURE 4 | Mean peroxidase activity ( \pm SE) for control and injured $P$. cylindrica at $(\mathbf{A})$ ambient $\left(27^{\circ} \mathrm{C}\right)$ and $(\mathbf{B})$ elevated $\left(32^{\circ} \mathrm{C}\right)$ water temperature over time post-injury.

role, upon injury was approximately 25 -fold higher than control levels, whereas phenoloxidase activities were just 2- to 4.5 -fold higher, suggestive of their toxicity and tight regulation due to the potential for self-harm.

Inducing a rapid immune response to efficiently seal a wound restores homeostasis and reduces the likelihood of infection, and therefore promotes survival. Using proteolytic cascades enables rapid immune activation, by-passing transcription. Given the energetic cost and the autoimmune risk of inducing an immune response (Lee, 2006; Palmer, 2018) benefits of P. cylindrica mounting a response to injury must out-weigh the costs incurred or the risk of not doing so (Lazzaro and Rolff, 2011). Therefore, under ambient and healthy control conditions, P. cylindrica has the resources available to mount an effective immune response and to mitigate autoimmunity. However, decreased activity of enzymes after the immune response, as compared to constituent immunity levels, are suggestive of the cost of heightened immunity (Harvell, 1990). The immediacy of the coral immune response is characteristic of innate immunity (Palmer et al., 2008, 2011c) and highlights how easy it is to miss a coral immune peak. Caution should therefore be taken to avoid underestimating or misinterpreting a coral immune response in studies where sampling times are delayed (e.g., van de Water et al., 2015b; Wright et al., 2016).

\section{Immune Trade-Offs With Warmer Water}

Warmer water, within normal summer ranges, enhanced constituent immunity of $P$. cylindrica controls and suppressed the immune response of injured samples. These data, compared to those of ambient conditions, indicate a shift in immune strategy with warmer water. This provides further evidence that coral holobiont immune systems are responsive-phenotypically plastic-to environmental shifts (e.g., Mydlarz et al., 2008; Palmer et al., 2011c; Pinzón et al., 2015; Palmer, 2018). Such temperatureinduced immune modulation and consequent shift in immune strategy is likely the result of trade-offs between maintaining optimal health and the costs incurred in doing so-both energetic and autoimmune (Sadd and Schmid-Hempel, 2009; Lazzaro and Rolff, 2011; Palmer, 2018).

The gradual investment into constituent immunity with warmer water may represent a relatively low-cost strategy to maintain homeostasis and minimize the necessity of costly 
and dangerous immune responses (Lee, 2006; Palmer, 2018). Investment into constituent immunity with temperature change is supported by the direct relationship of high coral constituent immunity with low disease and bleaching susceptibility (Palmer et al., 2010, 2012). Such immuno-dynamics are suggestive of the cross-tolerance phenomenon, whereby exposure to one type of disturbance, e.g., adverse environmental conditions, enhances protection against concurrent disturbances, such as infection or injury (Foyer et al., 2016).

Elevating constituent immune activity with the environmental cue of warmer water seems an appropriate strategy since both disease and bleaching pose higher threats during summer months (e.g., Sato et al., 2009). Therefore, there is the potential that $P$. cylindrica has adapted to modulate immunity-i.e., enhance constituent immune function- in order to increase survival during warmer conditions (Palmer, 2018). However, the generalized protection afforded by increased investment into constituent immunity and consequent cross-tolerance will come at a cost to other biological functions (Harvell, 1990; Sheldon and Verhulst, 1996). Such costs could be manifested as an inhibition of an effective immune response to acute, localized perturbations, such as injury and as observed in this study. Alternatively, or additionally, costs of elevated constituent immunity may be exhibited by compromised reproductive output or growth. However, in this study it is impossible to determine the evolutionary-scale influences and trade-offs from the physiological ones (Harvell, 1990; Sadd and Schmid-Hempel, 2009).

With warmer water, the immune response to injury occurred at $24 \mathrm{~h}$ with both mono and $o$-diphenoloxidase activities. In this temperature-induced delayed immune response, heightened activity was present but limited for $p$-diphenoloxidase and absent for peroxidase. The lack of immune response within $1 \mathrm{~h}$ of injury under warmer water suggests that implementing an immune response would be too costly. While variable through time, activity of the antioxidant peroxidase did not demonstrate a clear response to either temperature or injury. This suggests that the temperature changes in this experiment did not induce oxidative stress conditions (Jin et al., 2016) and/or that an alternative strategy may have been used to mitigate autoimmunity-possibly relying on the redox nature of melanin systhesis (Cerenius et al., 2010). After the immune response peak of injured samples, immune activity levels fell below constituent immunity levels of the control samples, indicative of the high cost of an immune response. The immune response, albeit delayed, appears to come at the cost of constituent immunity and suggests that $P$. cylindrica may be more vulnerable to disease and bleaching after physical injury during warmer water conditions. Such immune-energetics have implications for coral reefs during the summer months, when water temperatures are higher and cyclone activity raises the potential for physical injury.

Having a thermal cue for increasing constituent immunity in a tolerant coral seems appropriate given that elevated water temperature on coral reefs is associated with high photosynthetically active radiation (PAR; Brown and Dunne, 2015) and increased pathogen load and virulence (Harvell et al., 1999, 2002; Mydlarz et al., 2006). Two, possibly interacting, hypotheses of how water temperature triggers immune modulation include; (1) that during periods of elevated water temperature coral cells release "danger" components, such as nitric oxide and uric acid (Hawkins et al., 2014), which modulate immunity (Gallucci et al., 1999; Palmer, 2018) and (2) that the increase in water temperature is the cue in itself detected, potentially, by an anthozoan endocrine system yet-to-be thoroughly explored (Tarrant, 2015), which signals the immunity network. Regardless of the mechanism, inducing melanin synthesis pathways with warmer water may be particularly helpful as melanin is a photoprotective, radical-scavenging, brown to black pigment (Meredith et al., 2006) that is located within mobile coral cells (Palmer et al., 2008). Melanin synthesis pathway activity therefore has the potential to mitigate coral bleaching by affording photoprotection of Symbiodinium spp. (Palmer et al., 2010).

Consistent with a role in mitigating coral bleaching, increased prophenoloxidase activity (the zymogen form of phenoloxidase) has been documented in bleached Montastraea faveolata as compared to controls (Mydlarz et al., 2009). However, results of studies of other coral species at various stages of thermal stress are highly variable (e.g., Palmer et al., 2011a,c; Pinzón et al., 2015; van de Water et al., 2016). Variability in phenoloxidase activities both among and within coral species during thermal stress is likely the result of the physiological, ecological and historical context of the coral, leading to different immune strategies and energetic trade-offs (Sadd and Schmid-Hempel, 2009; Palmer, 2018).

Coral immunity is intrinsically linked to ecological-scale patterns of coral health and ultimately, therefore, coral reef resilience (Palmer, 2018). This study demonstrates that $P$. cylindrica is able to make physiological adjustments in response to environmental cues in order to promote survival. The potential for corals to demonstrate crosstolerance provides a tantalizing avenue of exploration as we seek to effectively conserve, restore and manage coral reefs.

\section{AUTHOR CONTRIBUTIONS}

$\mathrm{CP}$ conceived, designed, implemented, conducted the research and wrote the paper.

\section{FUNDING}

Research funding was provided by a Graduate Research School Grant, James Cook University, awarded to CP and a Natural Environment Research Council (NERC) UK grant and studentship to J. Bythell and CP, respectively.

\section{ACKNOWLEDGMENTS}

I would like to thank John Bythell and Bette Willis for comments on early drafts and Allison Paley for field assistance. A version of this research first appeared in CV Palmer's $\mathrm{PhD}$ thesis (Palmer, 2010). 


\section{REFERENCES}

Brown, B. E., and Dunne, R. P. (2015). Coral Bleaching: the roles of sea temperature and solar radiation," in Diseases of Cora, eds C. M. Woodley, C. A. Downs, A. W. Bruckner, J. W. Porter, and S. B. Galloway (Hoboken, NJ: John Wiley \& Sons, Inc.), 266-283.

Cerenius, L., Kawabata, S. I., Lee, B. L., Nonaka, M., and Söderhäll, K. (2010). Proteolytic cascades and their involvement in invertebrate immunity. Trends Biochem. Sci. 35, 575-583. doi: 10.1016/j.tibs.2010.04.006

Foyer, C. H., Rasool, B., Davey, J. W., and Hancock, R. D. (2016). Cross-tolerance to biotic and abiotic stresses in plants: a focus on resistance to aphid infestation. J. Exp. Bot. 67, 2025-2037. doi: 10.1093/jxb/erw079

Fuess, L. E., Weil, E., Grinshpon, R. D., and Mydlarz, L. D. (2017). Life or death: disease-tolerant coral species activate autophagy following immune challenge. Proc. R. Soc. B. 284:20170771. doi: 10.1098/rspb.2017.0771

Gallucci, S., Lolkema, M., and Matzinger, P. (1999). Natural adjuvants: endogenous activators of dendritic cells. Nat. Med. 5, 1249-1255. doi: 10.1038/15200

Harvell, C. D. (1990). The ecology and evolution of inducible defenses. Q. Rev. Biol. 65, 323-340. doi: 10.1086/416841

Harvell, C. D., Kim, K., Burkholder, J. M., Colwell, R. R., Epstein, P. R., Grimes, D. J., et al. (1999). Emerging marine diseases-climate links and anthropogenic factors. Science 285, 1505-1510. doi: 10.1126/science.285.5433.1505

Harvell, C. D., Mitchell, C. E., Ward, J. R., Altizer, S., Dobson, A. P., Ostfeld, R. S., et al. (2002). Climate warming and disease risks for terrestrial and marine biota. Science 296, 2158-2162. doi: 10.1126/science. 1063699

Hawkins, T. D., Krueger, T., Becker, S., Fisher, P. L., and Davy, S. K. (2014). Differential nitric oxide synthesis and host apoptotic events correlate with bleaching susceptibility in reef corals. Coral Reefs 33, 141-153. doi: 10.1007/s00338-013-1103-4

Hawkins, T. D., Krueger, T., Wilkinson, S. P., Fisher, P. L., and Davy, S. K. (2015). Antioxidant responses to heat and light stress differ with habitat in a common reef coral. Coral Reefs 34, 1229-1241. doi: 10.1007/s00338-015-1345-4

Hughes, T. P., Anderson, K. D., Connolly, S. R., Heron, S. F., Kerry, J. T., Lough, J. M., et al. (2018b). Spatial and temporal patterns of mass bleaching of corals in the Anthropocene. Science 359, 80-83. doi: 10.1126/science.aan8048

Hughes, T. P., Kerry, J. T., Baird, A. H., Connolly, S. R., Dietzel, A., Eakin, C. M., et al. (2018a). Global warming transforms coral reef assemblages. Nature. 556, 492-496. doi: 10.1038/s41586-018-0041-2

Jin, Y. K., Lundgren, P., Lutz, A., Raina, J. B., Howells, E. J., Paley, A. S., et al. (2016). Genetic markers for antioxidant capacity in a reef-building coral. Sci. Adv. 2:e1500842. doi: 10.1126/sciadv. 1500842

Lazzaro, B. P., and Rolff, J. (2011). Immunology. Danger, microbes, and homeostasis. Science 332, 43-44. doi: 10.1126/science. 1200486

Lee, K. A. (2006). Linking immune defenses and life history at the levels of the individual and the species. Integr. Comp. Biol. 46, 1000-1015. doi: $10.1093 /$ icb/icl049

Marshall, P. A., and Baird, A. H. (2000). Bleaching of corals on the Great Barrier Reef: differential susceptibilities among taxa. Coral Reefs 19, 155-163. doi: $10.1007 / \mathrm{s} 003380000086$

Meredith, P., Powell, B. J., Riesz, J., Nighswander-Rempel, S. P., Pederson, M. R., and Moore, E. G. (2006). Towards structure-property-function relationships for eumelanin. Soft Matter 2, 37-44. doi: 10.1039/B511922G

Miller, D., Hemmrich, G., Ball, E., Hayward, D., Khalturin, K., Funayama, N., et al., (2007). The innate immune repertoire in Cnidaria - ancestral complexity and stochastic gene loss. Genome Biol. 8:R59. doi: 10.1186/gb-2007-8-4-r59

Moya, A., Huisman, L., Ball, E., Hayward, D., Grasso, L., Chua, C., (2012). Whole transcriptome analysis of the coral Acropora millepora reveals complex responses to $\mathrm{CO} 2$-driven acidification during the initiation of calcification. Mol. Ecol. 21, 2440-2454. doi: 10.1111/j.1365-294X.2012.05554.x

Mydlarz, L. D., Couch, C. S., Weil, E., Smith, G., and Harvell, C. D. (2009). Immune defenses of healthy, bleached and diseased Montastraea faveolata during a natural bleaching event. Dis. Aquat. Org. 87, 67-78. doi: 10.3354/dao02088

Mydlarz, L. D., Fuess, L. E., Mann, W. T., Pinzón, C. J. H., and Gochfeld, D. J. (2016). "Cnidarian immunity: from genomes to phenomes," in The Cnidaria, Past, Present and Future, eds S. Goffredo and Z. Dubinsky (Springer International Publishing), 441-466. Available online at: https://www.springer. com/gb/book/9783319313030
Mydlarz, L. D., Holthouse, S. F., Peters, E. C., and Harvell, C. D. (2008). Celluar responses in sea fan corals: granular amoebocytes react to pathogen and climate stressors. PLoS ONE 3:e1811. doi: 10.1371/journal.pone.0001811

Mydlarz, L. D., Jones, L. E., and Harvell, C. D. (2006). Innate Immunity, environmental drivers, and disease ecology of marine and freshwater invertebrates. Annu. Rev. Ecol. Evol. Syst. 37, 251-288. doi: 10.1146/annurev.ecolsys.37.091305.110103

Mydlarz, L. D., and Palmer, C. V. (2011). The presence of multiple phenoloxidases in Caribbean reef-building corals. Comp. Biochem. Physiol. A Mol. Integr. Physiol. 159, 372-378. doi: 10.1016/j.cbpa.2011.03.029

Palmer, C. V. (2018). Immunity and the coral crisis. Commun. Biol. 1:91.

Palmer, C., Bythell, J. C., and Willis, B. (2012). Enzyme activity demonstrates multiple pathways of innate immunity in Indo-Pacific anthozoans. Proc. R. Soc. Lond. B Biol. Sci. 279, 3879-3887. doi: 10.1098/rspb.2011.2487

Palmer, C., Mydlarz, L., and Willis, B. (2008). Evidence of an inflammatory-like response in non-normally pigmented tissues of two scleractinian corals. Proc. $R$ Soc. B 275, 2687-2693. doi: 10.1098/rspb.2008.0335

Palmer, C. V. (2010). Biological Mechanisms of Scleractinian Immunity [Doctorate Thesis]. Newcastle University and James Cook University.

Palmer, C. V., Bythell, J. C., and Willis, B. L. (2010). Immunity parameters of reef corals underpin bleaching and disease susceptibility. Federation Am. Soc. Exp. Biol. 24, 1935-1946. doi: 10.1096/fj.09-152447

Palmer, C. V., Bythell, J. C., and Willis, B. L. (2011a). A comparative study of phenoloxidase activity in diseased and bleached colonies of the coral Acropora millepora. Dev. Comp. Immunol. 10, 1098-1101. doi: 10.1016/j.dci.2011.04.001

Palmer, C. V., McGinty, E. S., Cummings, D., Bartels, E., and Mydlarz, L. D. (2011c). Patterns of coral ecological immunology: variation in the responses of Caribbean corals to elevated temperature and a pathogen elicitor. J. Exp. Biol. 15, 4240-4249. doi: $10.1242 /$ jeb.061267

Palmer, C. V., Modi, C. K., and Mydlarz, L. D. (2009b). Coral fluorescent proteins as antioxidants. PLoS ONE 4:e7298. doi: 10.1371/journal.pone.0007298

Palmer, C. V., and Traylor-Knowles, N. (2012). Towards an integrated network of coral immune mechanisms. Proc. R. S. Lond. Series B Biol. Sci. 279, 4106-4114. doi: $10.1098 /$ rspb.2012.1477

Palmer, C. V., Traylor-Knowles, N. G., Willis, B. L., and Bythell, J. C. (2011b). Corals use similar immune cells and wound-healing processes as those of higher organisms. PLOS ONE 6:e23992. doi: 10.1371/journal.pone.00 23992

Pastori, G. M., and Foyer, C. H. (2002). Common components, networks, and pathways of cross-tolerance to stress. the central role of "Redox" and abscisic acid-mediated controls. Plant Physiol. 129, 460-468. doi: 10.1104/pp.011021

Pinzón, J. H., Kamel, B., Burge, C. A., Harvell, C. D., Medina, M., Weil, E., et al. (2015). Whole transcriptome analysis reveals changes in expression of immune-related genes during and after bleaching in a reef-building coral. $R$. Soc. Open Sci. 2:140214. doi: 10.1098/rsos.140214

Sadd, B. M., and Schmid-Hempel, P. (2009). Principles of ecological immunology. Evol. Appl. 2, 113-121 doi: 10.1111/j.1752-4571.2008.00 057.x

Sato, Y., Bourne, D. G., and Willis, B. L. (2009). Dynamics of seasonal outbreaks of black band disease in an assemblage of Montipora species at Pelorus Island (Great Barrier Reef, Australia). Proc. R. Soc. B Biol. Sci. 276, 2795-2803. doi: $10.1098 /$ rspb.2009.0481

Sheldon, B. C., and Verhulst, S. (1996). Ecological immunology: costly parasite defences and trade-offs in evolutionary ecology. Trends Ecol. Evol. 11, 317-321. doi: 10.1016/0169-5347(96)10039-2

Sogin, E. M., Putnam, H. M., Anderson, P. E., and Gates, R. D. (2016). Metabolomic signatures of increases in temperature and ocean acidification from the reef-building coral, Pocillopora damicornis. Metabolomics 12:71. doi: 10.1007/s11306-016-0987-8

Tarrant, A. M. (2015). "Endocrine-like signaling in corals," in Diseases of Coral, eds C. M. Woodley, C. A. Downs, A. Bruckner, J. Porter, and S. B. Galloway (Hoboken, NJ: John Wiley and Sons, Inc.), 138-149.

Tauber, A. I. (2015). Reconceiving autoimmunity: an overview. J. Theor. Biol. 375, 52-60. doi: 10.1016/j.jtbi.2014.05.029

Traylor-Knowles, N., Rose, N. H., Sheets, E. A., and Palumbi, S. R. (2017). Early transcriptional responses during heat stress in the coral Acropora hyacinthus. Biol. Bull. 232, 91-100. doi: 10.1086/692717 
van de Water, J. A. J. M., Ainsworth, T. D., Leggat, W., Bourne, D. G., Willis, B. L., and van Oppen, M. J. H. (2015b). The coral immune response facilitates protection against microbes during tissue regeneration. Mol. Ecol. 24, 3390-3404. doi: 10.1111/mec.13257

van de Water, J. A. J. M., Lamb, J. B., Heron, S. F., van Oppen, M. J. H., and Willis, B. L. (2016). Temporal patterns in innate immunity parameters in reefbuilding corals and linkages with local climatic conditions. Ecosphere 7:e01505. doi: $10.1002 /$ ecs2.1505

van de Water, J. A., Leggat, W., Bourne, D. G., van Oppen, M. J., Willis, B. L., and Ainsworth, T. D. (2015a). Elevated seawater temperatures have a limited impact on the coral immune response following physical damage. Hydrobiologia 759, 201-214. doi: 10.1007/s10750-015-2243-z

van Woesik, R., Sakai, K., Ganase, A., and Loya, Y. (2011). Revisiting the winners and the losers a decade after coral bleaching. Mar. Ecol. Prog. Ser. 434, 67-76. doi: 10.3354/meps09203
Wright, R. M., Kenkel, C. D., Dunn, C. E., Shilling, E. N., Bay, L. K., and Matz, M. V. (2016). Higher stress and immunity responses are associated with higher mortality in reef-building coral exposed to a bacterial challenge. Nature. bioRxiv:059444. doi: 10.1101/059444

Conflict of Interest Statement: The author declares that the research was conducted in the absence of any commercial or financial relationships that could be construed as a potential conflict of interest.

Copyright (C) 2018 Palmer. This is an open-access article distributed under the terms of the Creative Commons Attribution License (CC BY). The use, distribution or reproduction in other forums is permitted, provided the original author $(s)$ and the copyright owner(s) are credited and that the original publication in this journal is cited, in accordance with accepted academic practice. No use, distribution or reproduction is permitted which does not comply with these terms. 